\title{
Retrieving names in old age: Short- and (very) long-term effects of repetition
}

\author{
ELIZABETH A. MAYLOR \\ University of Warwick, Coventry, England
}

\begin{abstract}
Two experiments are reported that examine the effects of repetition on name retrieval in younger adults (in their 50s and 60s) and older adults (in their 70s and 80s). In Experiment 1, the subjects were asked to name a set of famous faces four times over the course of a 1-h session. Younger subjects produced significantly more correct responses than did older subjects. There was significant improvement with repeated attempts at naming, with younger and older subjects benefiting equally in terms of increasing numbers of correct responses across the session. In contrast, there was a highly significant age deficit in picture recognition over a similar retention interval. A qualitative analysis of naming responses (full name vs. part of the name) provided support for the view that aging and nonrecent use have equivalent effects on retrieval. In Experiment 2, younger subjects (but not older subjects) were significantly more likely to correctly name famous faces that they had seen 22 months previously than to correctly name new famous faces. In contrast, older subjects (but not younger subjects) were significantly more likely to produce erroneous names to famous faces that they had seen 22 months previously than to new famous faces. It is concluded that repetition priming may be relatively unaffected by aging over short retention intervals (Experiment 1) but not over a very long retention interval (Experiment 2).
\end{abstract}

Memory tasks such as free recall and recognition are examples of explicit memory; that is, performance on the task requires conscious recollection of a previous experience. In contrast, implicit memory is revealed when performance on a task is influenced by a previous experience but in the absence of conscious or intentional recollection of that experience (Graf \& Schacter, 1985). Recent evidence on implicit memory comes largely from studies of repetition priming, which refers to the facilitation in the processing of a stimulus (either improved accuracy or reduced latency) as a function of a recent encounter with the same stimulus (see Schacter, 1987, for a review).

Implicit memory can be dissociated from explicit memory in a number of ways. First, performance on implicit and explicit memory tasks is affected differentially by various experimental manipulations. One such factor that is relevant to the present study is retention interval. For ex-

This research was reported at a meeting of the Experimental Psychology Society, Cambridge, England, April 1995. This article was written while the author was employed at the Medical Research Council's Applied Psychology Unit, Cambridge, UK. I am grateful to Patrick Rabbitt for access to volunteers at North East Age Research (University of Newcastle-upon-Tyne) and to Catherine Brennard, Joyce Hunter, Lynn McInnes, and Louise Turner for their assistance in the recruiting and testing of subjects. I also thank Andy Calder for some of the stimuli used in Experiment 2 and Hilary Green for assistance with data analysis. David Mitchell and an anonymous reviewer provided helpful comments on an earlier version of the article. Correspondence concerning this article should be addressed to the author at the Department of Psychology, University of Warwick, Coventry, CV4 7AL, UK (e-mail: elizabeth.maylor@warwick.ac.uk).

—Accepted by previous editor, Geoffrey R. Loftus ample, Mitchell and Brown (1988) examined picturenaming latencies in university students and found that previously named pictures were named faster than were new pictures. This repetition priming effect showed no decline over a 6-week retention interval, whereas recognition memory for the pictures declined significantly over the same delay.

There is evidence that priming can persist over intervals considerably longer than 6 weeks. Kolers (1976) demonstrated that students were faster at reading typographically inverted text that they had read 13 to 15 months earlier than at reading new text. Also, Sloman, Hayman, Ohta, Law, and Tulving (1988) showed that priming in a word fragment completion experiment with student subjects was still present after 16 months. Recall and recognition data were not available over the same interval, but the authors noted that "it seems reasonable to assume that the longevity of retention is greater for primed fragment completion than for the measures of retention of episodic information" (p. 237).

A second line of evidence in support of the explicit/ implicit memory distinction comes from studies of amnesic patients, who are severely impaired on explicit memory tests but less impaired (and sometimes normal) on various implicit tests (as summarized by Schacter, 1987). Cave and Squire (1992), for example, reported that amnesic patients showed the same degree of repetition priming as did controls in a picture-naming experiment after a delay of 7 days. In contrast, recognition memory for the pictures was much poorer in the amnesics than in the controls. The authors concluded from their results that "longlasting priming and recognition memory depend on separate brain systems" (p. 518). 
In the aging literature, similar dissociations have been observed between preserved implicit memory and impaired explicit memory (see reviews by Craik \& Jennings, 1992; Duchek \& Balota, 1993; Light, 1991; Schacter, Kihlstrom, Kaszniak, \& Valdiserri, 1993). However, as noted by Salthouse (1991) and others, age differences in implicit measures of memory may not reach significance, but they usually favor the young. This raises the possibility that there is a slight decline in implicit memory with increasing age that individual studies are unable to detect because of insufficient power (see Brown \& Mitchell, 1994 , for a similar argument with respect to levels of processing and implicit memory). La Voie and Light (1994), therefore, conducted a meta-analysis on repetition priming effects in younger and older adults. The overall effect size was $d=.304$, which was smaller than that for either recognition $(d=.497)$ or recall $(d=.968)$. However, the confidence interval did not include zero, so the authors rejected the null hypothesis that repetition priming is unaffected by old age.

An alternative possibility is that implicit memory tasks are contaminated by intrusions from explicit memory, as acknowledged by La Voie and Light (1994): "Young adults perform better than older adults on tasks requiring deliberate recollection. They may consequently be more likely to notice that they are producing or encountering previously seen list members while performing priming tasks, and having noticed this, they may be more likely to continue doing so intentionally" (p. 550). La Voie and Light restricted their meta-analysis to linguistic tasks and materials (e.g., homophone spelling, word stem completion) that may be particularly susceptible to such contamination. In contrast, picture-naming tasks in which latency is the dependent measure are unlikely to be contaminated in this way, because subjects cannot use their recollection of a stimulus to affect the priming measure (Mitchell, 1993). The results from these studies are striking: Picture recognition was significantly impaired in older subjects relative to younger subjects, whereas repetition priming showed no reliable age differences (Mitchell, 1989; Mitchell, Brown, \& Murphy, 1990).

Dissociations between implicit and explicit memory with aging can be interpreted within a multiple memory systems framework in which "implicit and explicit forms of memory depend on different memory systems that are associated with distinct regions of the brain" (Schacter, 1995, p. 815; see also Nyberg \& Tulving, 1996). The hippocampus and its related structures are associated with explicit memory tests of recall and recognition, whereas other brain regions support implicit memory, including priming (see Squire \& Knowlton, 1995, for a summary), with the former but not the latter being adversely affected by old age. But an alternative account is provided by a processing framework (see, e.g., Jacoby, 1991), such that age has a detrimental effect on consciously controlled memory processing but leaves automatic processing intact (Jennings \& Jacoby, 1993). It is difficult to distinguish between these views, and, "in any event, the choice of whether to interpret dissociations in terms of processes or in terms of memory systems is most likely a matter of difference in perspective" (La Voie \& Light, 1994, p. 540).

The main aim of the present study was to compare repetition effects in middle-aged adults $(50 \mathrm{~s}-60 \mathrm{~s})$ and elderly adults (70s-80s), over both short and (very) long retention intervals. The task selected for investigation was a particular form of picture-naming-that is, the identification of familiar faces. This was chosen for a number of reasons. First, there is a highly successful informationprocessing model of face identification by Bruce and Young (1986) in which there are sequential but distinct functional subcomponents or stages, with failure at any one of them resulting in failure to produce a person's name (see Valentine, Brennen, \& Brédart, 1996, for a summary of more recent support for the model). Each face that a person knows is represented by a separate face recognition unit (FRU). These FRUs are stored descriptions of familiar faces and are abstract in that they respond to a variety of poses and expressions. They are activated after the initial structural encoding of a facial pattern if there is sufficient overlap between the stimulus face and the stored description. A face is recognized as familiar if such activation exceeds the threshold for that particular FRU. Only then is it possible to access the store of semantic information about a person's identity (person identity node, or PIN), such as his or her occupation, whether he or she is alive or dead, etc. Activation of the PIN leads, in turn, to the final stage of face identification, which is the retrieval of the person's name. For example, Maylor (1990) found that, with limited time to identify famous faces (50 sec per face), adults aged $50-80$ successfully reached the FRU stage on approximately $80 \%$ of occasions, the PIN stage on $75 \%$ of occasions, and the name retrieval stage on $52 \%$ of occasions (see also Maylor, 1997).

Repetition priming in this context of face identification is assumed to occur as follows: If faces are presented for naming under speeded conditions (say, $10 \mathrm{sec}$ per face), some faces will be named but others will not (processing of the latter perhaps reaching the FRU or PIN stage). When these faces are re-presented later for naming under the same conditions, less time will be required to reach the stage previously achieved on the first attempt (repetition priming), thereby allowing more time to negotiate the next stage in the process (e.g., from FRU to PIN or from PIN to name). This is an implicit memory task, because it requires subjects to identify a stimulus without explicitly asking them for conscious recollection of any previous exposure to the stimulus as they do so. It is argued that an increase in the number of correct naming responses across the two occasions can be taken as evidence of implicit memory for processing during the initial encounter. This assumes (1) that there is no further processing of the stimulus in the interval between presentations and (2) that there is no general effect of practice in the processing of familiar faces. Arguments and evidence in support of these two assumptions will be presented below. 
The second reason for selecting face identification for the present investigation was that it has been argued that a strong test of the preservation of implicit memory in old age is one that involves a task known to be substantially impaired by aging (see Parkin, 1993). Older people often report particular difficulty in the retrieval of proper names (see, e.g., Rabbitt, Maylor, McInnes, Bent, \& Moore, 1995), and this is consistent both with diary studies (Burke, MacKay, Worthley, \& Wade, 1991; G. Cohen \& Faulkner, 1986) and laboratory data (see, e.g., Rastle \& Burke, 1996). In fact, age-related impairments have been demonstrated at all three main stages of the face identification process (Maylor, 1990, 1997).

Third, with people's names as responses, there is the opportunity to examine partial name retrieval (i.e., first name only or surname only vs. full name) as a function of aging and priming. Maylor and Valentine (1992) and Maylor (1995) asked subjects to produce at least the surname when identifying familiar faces. Although not reported, in both studies the proportion of correct responses that included the first name as well as the surname was approximately $10 \%$ higher for younger subjects than for older subjects. This result can be used as a tool to compare the effects of aging and priming on name retrieval. Most current models of proper name retrieval (see, e.g., Brédart, Valentine, Calder, \& Gassi, 1995; Bruce \& Young, 1986; Burton, Bruce, \& Johnston, 1990) make no specific predictions regarding old age and priming. However, one model suggests that these two factors should have similar effects (although opposite in direction). On the basis of an interactive activation model of speech production, MacKay and Burke (1990) proposed that word retrieval problems are due to weakened connections between nodes. For example, a "tip of the tongue" state would arise if links between lexical nodes (in the semantic system) and phonological nodes were too weak to produce sufficient activation in the phonological system. Burke et al. (1991) identified three factors thought to have the same effect of weakening connections between nodes: aging, nonrecent use, and infrequent use. Since nonrecent use is equivalent to lack of priming, one would predict from their model that younger and older subjects should differ from each other in much the same way as primed and unprimed conditions differ. So, just as younger subjects are faster and more successful at retrieving names (particularly full names) than are older subjects (Maylor, 1995; Maylor \& Valentine, 1992), repetition priming should produce the same qualitative pattern of results.

To summarize the present study, two experiments are reported in which younger and older adults were compared in their ability to retrieve the names of famous people, after having named or attempted to name some of the faces, either earlier in the session (Experiment 1) or 22 months previously (Experiment 2 ). The overall objectives were to provide further evidence for (1) dissociations between explicit and implicit memory by manipulating age and retention interval and (2) similar but inversely related effects of aging and repetition on performance.

\section{GENERAL METHOD}

\section{General Information on Subjects}

In both experiments to be reported, subjects were selected from a panel of volunteers aged over 50 who were participating in a longitudinal study of cognitive aging at North East Age Research, based at Newcastle University. Each volunteer had responded to media advertisements and had visited the research center on several previous occasions in order to participate in testing sessions. Subjects received $£ 4$ (approximately $\$ 6$ ) on each of their visits to cover traveling expenses.

Two groups of subjects ( $50 \mathrm{~s}-60 \mathrm{~s}$ and $70 \mathrm{~s}-80 \mathrm{~s}$ ) were recruited for each of the present experiments. In both the younger and older age groups, there were approximately twice as many female subjects as male subjects. Subjects in the two age groups were matched as closely as possible in terms of their scores on the vocabulary subtest of the Wechsler Adult Intelligence Scale-Revised (WAIS-R; Wechsler, 1981). This was adapted slightly for use with British subjects so that the maximum score was 74 . Subject details for each experiment are summarized in Table 1 . The WAIS-R vocabulary scores of younger and older subjects did not differ significantly in either of the experiments (both $t s<1$ ). These scores were collected as part of the longitudinal study (see Rabbitt, Donlan, Bent, McInnes, \& Abson, 1993).

\section{General Information on Stimuli}

Black-and-white photographs of famous faces were made into slides, with templates, where necessary, to conceal as much clothing and background as possible. Particular care was taken to select people who should have been well known to subjects in their 50s-80s.

\section{EXPERIMENT 1}

In this first experiment, a set of faces was repeatedly presented for naming. Two points should be noted: First, the interval between presentations was filled by a demanding distractor task in order to prevent further thoughts about the stimuli during the intervening period. (Indeed, there was no obvious incentive to continue processing after each presentation, since the subjects had no reason to expect that they would see the same set of faces more than once.) Second, naming familiar faces is not a task that

Table 1

Subject Characteristics for Experiments 1 and 2

\begin{tabular}{|c|c|c|c|c|c|c|}
\hline Subjects & $n$ & Age Range & $\begin{array}{c}\text { Mean } \\
\text { Age }\end{array}$ & $S D$ & $\begin{array}{c}\text { Mean } \\
\text { Vocabulary* }\end{array}$ & $S D$ \\
\hline \multicolumn{7}{|c|}{ Experiment 1} \\
\hline Younger & 43 & $51.8-61.7$ & 57.3 & 2.6 & 52.5 & 8.5 \\
\hline Older & 43 & $70.0-83.0$ & 74.6 & 3.4 & 52.4 & 8.5 \\
\hline \multicolumn{7}{|c|}{ Experiment 2} \\
\hline All younger & 57 & $53.5-63.5$ & 59.3 & 2.4 & 53.6 & 8.6 \\
\hline Younger 2 nd- 1 & 32 & 53.5 & 58 & 2. & 53 & 8.5 \\
\hline Younger 1st-timers & 25 & $55.4-63.1$ & 59.9 & 1.9 & 53.2 & 9.0 \\
\hline All older & 59 & $71.0-84.8$ & 76.1 & 3.6 & 53.9 & 8.1 \\
\hline Older 2 nd & 34 & $71.8-84.8$ & & 3.7 & 52.8 & 8.6 \\
\hline Older 1 st-timers & 25 & $71.0-84.6$ & 75.8 & 3.6 & 55.4 & 7.2 \\
\hline
\end{tabular}

*Scores on the vocabulary subtest of the WAIS-R. Maximum score $=\overline{74}$. 
benefits from a general practice effect, as is shown by the data from an unpublished study. ${ }^{1}$ This is perhaps unsurprising in view of the fact that it is a well-practiced everyday task that is easy to understand. Thus, any improvement in naming performance that is observed over repeated attempts to name the same set of faces (i.e., from blank responses on earlier occasions to correct responses on later occasions) is evidence of repetition priming, as defined by the facilitation in the processing of a stimulus as a function of a recent encounter with the same stimulus (Schacter, 1987). On the other hand, if there is no implicit memory for earlier processing, no improvement in performance should be observed (i.e., blank responses remain blank; correct responses remain correct). The main question is, therefore, whether younger and older subjects benefit equally from repetition. For comparison, explicit memory over the same retention interval was assessed by a picture recognition task.

The other issue of interest is whether the effects of aging and repetition are qualitatively equivalent in terms of full versus partial name retrieval. In previous studies (Maylor, 1995; Maylor \& Valentine, 1992), subjects were instructed that they should produce the full name, if possible, but that the surname alone was "acceptable." Thus, it is possible that older subjects were less likely to produce the full name than were younger subjects, not because they were unable to retrieve the first name, but because they chose not to, when given the option. In the present experiment, therefore, subjects were specifically asked always to produce as much of the name as possible.

\section{Method}

Apparatus and Stimuli. The stimuli were 30 slides of famous male faces. The slides were projected from a Kodak carousel projector onto a large screen, so that each face measured approximately $1.25 \mathrm{~m}$ wide and $2.5 \mathrm{~m}$ high. Testing took place in a steeply banked lecture theater, such that all subjects had a clear view of the stimuli.

There were eight separate response sheets, two for each block of trials. The block number $(1,2,3$, or 4$)$ appeared in the top right-hand corner of each sheet. The two sheets for each block corresponded to Trials $1-15$ and Trials $16-30$, respectively. Each line of the response sheet began with the trial number, and this was then followed by a dotted line for the subject's response.

Design and Procedure. The experimental sessions lasted approximately $70 \mathrm{~min}$. The subjects were tested in groups of between 14 and 16. They were instructed that they would be doing two separate tasks - called the faces task and the category task-and that each task would be repeated several times. Nothing was said about whether the stimuli would be repeated or not. The instructions for the faces task were presented first. The subjects were told that they would see 30 slides on the screen, one at a time. Each slide showed a famous person's face, and the subjects' task was to write down the person's full name--in other words, both the first name and the surname. If they did not know the full name, they were asked to write down as much of the name as possible - that is, either the first name or the surname. They were told that they had only $10 \mathrm{sec}$ from the appearance of the slide to think of the name and write it down before the experimenter told them to "stop." However, it was stressed that this instruction was short-hand for: "If you have already started writing something, then finish your response and then stop. But do not start writing anything after being told to stop." They were then asked to fold the response sheet in such a way as to cover up their previous responses, ready for the next trial. Instructions for a simple prospective memory task were then given (see Maylor, 1993, for further details).

In the category task, the subjects were given the name of a category ("towns and cities anywhere in the world") and were asked to write down as many instances of that category as they could think of in the time available ( $4 \mathrm{~min}$ ).

After all the instructions had been read out twice, the experimental tasks began. The faces task was conducted four times, alternating with the category task, which was conducted three times (with the same category on each occasion).

Before presenting each slide in the faces task, the experimenter ensured that all of the subjects were ready to continue. The trial number was announced prior to the presentation of each slide for $10 \mathrm{sec}$. The instruction to "stop, and fold over" coincided with the disappearance of the slide. The stimuli were presented in a different order in each block. All of the subjects received the same order.

Picture recognition. This task was conducted during an earlier testing session as part of a longitudinal study of cognitive aging (see Rabbitt et al., 1993). Forty pictures taken from "Peanuts" cartoons (without words) were presented sequentially on slides, each for $2 \mathrm{sec}$. After further instructions, 10 of these pictures were then represented along with 10 similar distractors in a random order, each for $3 \mathrm{sec}$. The subjects were required to indicate which of these 20 pictures they had seen before. Picture recognition was tested in this way a further three times over the course of an experimental session, with other memory tests intervening between each set of 20 pictures ( 10 targets, 10 distractors). The average delay between initial presentation and recognition was approximately $40 \mathrm{~min}$.

\section{Results and Discussion}

The analyses reported here do not include the data from 2 subjects ( 1 younger, 1 older) who obviously misunderstood the instructions and produced the initial instead of the first name in response to each stimulus. The data from the remaining 84 subjects were coded into nine different categories, corresponding to the nine possible combinations of correct (C), erroneous (E), and blank (B) first names with $C, E$, and $B$ surnames. The mean percentages of responses for each of the four runs and for each age group are presented in the Appendix.

To summarize the general pattern of results, first, most responses were either fully correct $(\mathrm{CC})$ or completely blank (BB), with very few entirely erroneous (EE). Second, younger subjects produced more correct names than did older subjects. Third, performance improved over the four runs, as indicated by an overall increase in CC responses of $15.6 \%,{ }^{2}$ which considerably outweighed the overall increase in EE responses of $2.6 \%$. Finally, the improvement from Runs 1-4 was almost identical for younger and older subjects.

An analysis of variance (ANOVA) was conducted on the percentage of $\mathrm{CC}$ responses (i.e., correct first name and surname; see Table 2 for means), with age group (two levels) and run (four levels) as between- and within-subjects factors, respectively $\left(F_{1}\right.$ ratios). An items analysis ${ }^{3}$ was also conducted ( $F_{2}$ ratios) to ensure that any significant effects in the subjects analysis were not specific to particular items. Younger subjects produced significantly more $\mathrm{CC}$ responses than did older subjects $\left[F_{1}(1,82)=\right.$ 
Table 2

Experiment 1: Means ( $M$ ) and Standard Deviations (SD) of Percentages of Correct Full Name Responses (CC) and Correct Full Name Responses as Percentages of Responses in Which at Least Part of the Name was Correct [i.e., $\mathrm{CC} /(\mathrm{CC}+\mathrm{EC}+\mathrm{BC}+\mathrm{CE}+\mathrm{CB})]$

\begin{tabular}{|c|c|c|c|c|c|c|c|c|}
\hline \multirow[b]{2}{*}{ Subjects } & \multicolumn{2}{|c|}{ Run 1} & \multicolumn{2}{|c|}{ Run 2} & \multicolumn{2}{|c|}{ Run 3} & \multicolumn{2}{|c|}{ Run 4} \\
\hline & $M$ & $S D$ & $M$ & $S D$ & $M$ & $S D$ & $M$ & $S D$ \\
\hline \multicolumn{9}{|c|}{$\mathrm{CC}$} \\
\hline Younger & 48.8 & 20.9 & 56.9 & 20.8 & 62.4 & 19.9 & 64.3 & 20.2 \\
\hline Older & 24.4 & 20.1 & 33.1 & 20.7 & 37.6 & 21.5 & 40.1 & 22.3 \\
\hline \multicolumn{9}{|c|}{$\mathrm{CC} /(\mathrm{CC}+\mathrm{EC}+\mathrm{BC}+\mathrm{CE}+\mathrm{CB})$} \\
\hline Younger & 79.1 & 15.0 & 83.6 & 11.7 & 87.8 & 9.1 & 87.7 & 9.8 \\
\hline Older & 56.2 & 23.2 & 66.7 & 19.8 & 69.4 & 21.9 & 71.0 & 22.4 \\
\hline
\end{tabular}

$\left.29.97 ; F_{2}(1,29)=139.15\right]$, and $\mathrm{CC}$ responses increased significantly over the four runs $\left[F_{1}(3,246)=157.84\right.$; $F_{2}(1,29)=181.27 ;$ all $p$ s $\left.<.05\right]$. Age group did not interact with run $\left(F_{1}<1 ; F_{2}<1\right)$. In short, younger subjects consistently outperformed older subjects, and this was not because there were certain stimuli that were inappropriate for an older age group.

A potential complication is that parallel functions are difficult to interpret when overall levels of performance differ across age groups. For example, there may be a ceiling effect on improvement, particularly for younger subjects. The analysis by subjects was therefore repeated, with Run 1 performance included as a covariate, with the result that the interaction between age group and run remained nonsignificant $(F<1)$. Thus, when statistically matched for initial levels of performance, younger and older subjects did not differ in terms of the increase in CC responses from Run 1 to Run 4.

Looking in more detail at the subjects' responses, fewer correct first names were produced $(\mathrm{CC}+\mathrm{CE}+$ $\mathrm{CB}=48.3 \%$ of responses) than correct surnames (CC + $\mathrm{EC}+\mathrm{BC}=55.4 \%$ ). This difference was highly significant across both subjects and items $\left[F_{1}(1,82)=77.29\right.$; $F_{2}(1,29)=23.57$; both $p$ s <.05]. In contrast, the numbers of erroneous first name and surname responses did not differ $\left(7.0 \%\right.$ and $7.4 \%$, respectively; $\left.F_{1}<1\right)$. A possible explanation for the finding that correct surnames are easier to retrieve than correct first names is in terms of stimulus exposure. Thus, the names of famous people are usually encountered as either full names (e.g., Jimmy Carter) or as surnames only (President Carter) but almost never as first names alone (Jimmy).

Of greater interest here is the number of correct full name responses (CC) as a percentage of the responses in which at least part of the name was correct $(\mathrm{CC}+\mathrm{EC}+$ $\mathrm{BC}+\mathrm{CE}+\mathrm{CB})$. This was analyzed as a function of age group and run (see Table 2 for the means). ${ }^{4}$ Younger subjects produced a higher percentage of naming responses that were fully correct than did older subjects $\left[F_{1}(1,81)=\right.$ $\left.31.13 ; F_{2}(1,29)=62.57\right]$, and this percentage also increased over the four runs $\left[F_{1}(3,243)=24.55 ; F_{2}(1,29)=\right.$ 52.86 ; all $p \mathrm{~s}<.05]$. The interaction between age group and run was not significant $\left[F_{1}(3,243)=1.80 ; F_{2}(1,29)=\right.$ 2.90 ; both $p s>.05]$. These results confirm the unreported observations from previous studies that employed different instructions (Maylor, 1995; Maylor \& Valentine, 1992) - that is, the percentage of naming responses that included both the correct first name and the correct surname was greater for younger subjects than for older subjects. They also show that the same applies to later attempts at naming, in comparison with earlier attempts.

Picture recognition. Performance in the picture recognition task was measured by the hit rate (number of targets successfully recognized as a percentage of 40), the false alarm rate (number of distractors falsely recognized as a percentage of 40 ), and the difference between them (hits minus false alarms). In addition, nonparametric indices of signal detection sensitivity and response bias were obtained by applying Formula 2 from Grier (1971) and Formula 7 from Donaldson (1992), respectively.

The results are summarized in Table 3 . It can be seen that the hit rate was slightly higher (but not significantly) for younger subjects than for older subjects, whereas the false alarm rate was significantly higher for older subjects than for younger subjects. Thus, on the signal detection measures, younger subjects discriminated between targets and distractors significantly better than did older subjects, showing greater sensitivity with no change in response bias. Note that this aging pattern-namely, a nonsignificant effect on hits and a significant increase in false alarms, producing a significant decrease in sensitivity - has been observed in several studies of recog-

Table 3

Experiment 1: Picture Recognition Data

(Means and Standard Deviations) and Results of 2-Tailed $t$ Tests on the Difference Between Younger and Older Subjects

\begin{tabular}{|c|c|c|c|c|c|}
\hline & \multicolumn{2}{|c|}{ Younger Subjects } & \multicolumn{2}{|c|}{ Older Subjects } & \multirow[b]{2}{*}{ Difference } \\
\hline & $M$ & $S D$ & $M$ & $S D$ & \\
\hline Hit rate $(\%)$ & 81.5 & 12.3 & 77.7 & 14.5 & $t(84)=1.32$, n.s. ${ }^{*}$ \\
\hline False alarm rate $(\%)$ & 38.3 & 10.6 & 44.5 & 8.1 & $t(84)=-3.02$, sig. $\dagger$ \\
\hline Hit rate - FA rate & 43.2 & 17.0 & 33.2 & 14.3 & $t(84)=2.95$, sig. \\
\hline Sensitivity + & 0.801 & 0.086 & 0.751 & 0.100 & $t(84)=2.50$, sig. \\
\hline Bias $\S$ & -.469 & 0.338 & -.461 & 0.359 & $t(84)=-0.10$, n.s. \\
\hline
\end{tabular}

Note- ${ }^{*}$ not significant $(p>.05)$; ${ }^{\dagger}$ significant $(p<.05)$; ${ }^{\star} \mathrm{A}^{\prime}$ from Grier $(1971)$; ${ }^{\S} \mathrm{B}_{\mathrm{D}}{ }^{\prime \prime}$ from Donaldson (1992). 
nition memory for unfamiliar faces in the elderly (see, e.g., Ferris, Crook, Clark, McCarthy, \& Rae, 1980; Smith \& Winograd, 1978).

To summarize, the main conclusion from Experiment 1 is that younger and older subjects displayed parallel improvements in naming with repetition (implicit measure), despite age-related decline in picture recognition (explicit measure) over an approximately equivalent retention interval. ${ }^{5}$ (At the risk of circular argument, it is worth pointing out here that this pattern of results is evidence against contamination from explicit memory. Thus, if contamination was occurring, younger subjects' naming performance would have improved more with repetition than would have older subjects', on the basis of their significantly better explicit memory.) In addition, the effects of aging and repetition were similar but in opposite directions, in terms of the proportion of full name responses, as predicted from Burke et al.'s (1991) model.

It would be premature to conclude, on the basis of these results, that implicit memory is unaffected by aging, for at least two reasons. The first is that power analysis (J. Cohen, 1988) reveals that the power of Experiment 1 to detect an effect of size $d=.304$ (from La Voie \& Light's, 1994, meta-analysis) is rather low at 0.29 for an alpha level of .05 . The second is that the present experiment is limited to short retention intervals of up to an hour. It therefore remains a possibility that implicit memory is more adversely affected by aging over much longer retention intervals of months or years. So far, no one has examined priming effects in elderly populations over retention intervals of the scale employed in studies such as Kolers (1976) and Sloman et al. (1988).

\section{EXPERIMENT 2}

The aim of Experiment 2 was to extend the investigation of repetition effects in younger and older adults to a considerably longer retention interval-namely, 22 months. Age deficits in long-term explicit memory have been demonstrated in a number of studies with subjects of the same ages and from the same population as in the present experiments. For example, subjects who had participated in Maylor and Valentine's (1992) study were asked 8-10 weeks later to recall the names of the 24 very famous faces that they had been asked to name in the experiment. (In that particular study, subjects were always told the correct answers at the end of the original testing session.) Younger subjects recalled significantly more stimuli than did older subjects [means of $19.3 \%$ and $12.6 \%$, respectively; $t(58)=2.24, p<.05]$. Similarly, Maylor (1991) played television theme tunes to subjects and asked them to indicate whether they had heard them before or not. There was a significant age difference in tune recognition for programs that subjects reported watching years earlier [ $83.4 \%$ for younger subjects, $74.3 \%$ for older subjects; $t(67)=2.48, p<.05]$. In other words, significant age-related deficits have been shown in objective tests of long-term recall and recognition (explicit memory). The question of interest here is whether this is also the case for implicit memory, as measured by the effect on name retrieval of having previously encountered the same stimuli almost 2 years earlier.

Two features of the design of Experiment 2 should be noted in particular. The first is that the extremely long retention interval of 22 months should minimize any possibility of contamination from explicit memory. The second is that the naming task included three times as many new (unprimed) stimuli as old (primed) stimuli so as to discourage subjects from attempting to recall previous responses. This was an unlikely strategy anyway, because the task was the same as in Experiment 1-that is, naming under some time pressure (see Mitchell, 1993). Note that $10 \mathrm{sec}$ per stimulus is regarded as speeded in the context of face-naming latencies, which are typically much longer than object-naming latencies (see, e.g., Maylor, 1995).

\section{Method}

Subjects. Sixty-six of the subjects who participated in Experiment 1 were able and willing to take part in Experiment 2, which was conducted 22 months later. In this group of 2 nd-timers, there were 32 younger subjects and 34 older subjects (see Table 1). A further group of 50 1st-timers was recruited who had not previously participated in Experiment 1. These 1st-timers were selected to approximately match the 2 nd-timers in terms of age and WAIS-R vocabulary scores; there were 25 younger subjects and 25 older subjects in the 1st-timer group.

Apparatus and Stimuli. The stimuli were 120 slides of famous faces. Thirty of these slides were those used in Experiment 1 . The only difference between the original set of 30 (old stimuli) and the additional set of 90 (new stimuli) was the proportion of female faces ( 0 and .33 , respectively). Like the terms 2 nd-timer and 1 st-timer for subjects, old refers to stimuli used in both Experiments 1 and 2, whereas new refers to stimuli used in Experiment 2 only. The slides were divided into four sets of 30 , so that each set included 6,7 , or 8 old stimuli and either 7 or 8 female faces. All other details of apparatus and stimuli were as those in Experiment 1.

Design and Procedure. Subjects were tested in the same lecture theater as in Experiment 1, in groups of between 10 and 18. They were told that there were two separate tasks, called the faces task and the letter task, and that each task would be repeated several times. The instructions for these tasks were read out twice and were the same as in Experiment 1, except for the following changes. First, the simple prospective memory task was slightly altered (see Maylor, 1996, for further details). Second, in the category task (now called the letter task), subjects were asked to write down as many words as possible beginning with the letter $s$.

In the faces task, each stimulus appeared only once. The 120 stimuli (four blocks of 30 ) were presented in the same randomized order in each experimental session, with the exception of eight items (associated with the prospective memory task), which were changed from session to session.

\section{Results and Discussion}

The naming data were scored in terms of whether the surname was correct, erroneous, or blank. ${ }^{6}$ Percentages of correct, erroneous, and blank responses were calculated separately for old and new stimuli. ${ }^{7}$ The means are presented in Table 4. It can be seen that, consistent with the 
results of Experiment 1, younger subjects produced more correct responses than did older subjects. Note also that responses to old and new stimuli were very similar for 1 sttimers, indicating that the two sets of stimuli were well matched in terms of difficulty. More interestingly, there appears to be evidence of long-term priming, such that 2nd-timers produced more correct responses to old stimuli seen 22 months earlier than to new stimuli. The important question is whether these effects are the same for younger and older subjects.

Separate ANOVAs were conducted on correct, erroneous, and blank responses, with age group (younger vs. older) and experience (2nd-timers vs. 1st-timers) as between-subjects factors and stimulus type (old vs. new) as the within-subjects factor. For correct responses, there was a significant overall effect of age group, as expected [ $55.8 \%$ for younger subjects vs. $32.8 \%$ for older subjects; $F(1,112)=47.90, p<.05]$. The crucial interaction between experience and stimulus type (i.e., evidence of priming) was significant $[F(1,112)=17.01, p<.05]$, but this was qualified by a significant three-way interaction with age group $[F(1,112)=4.41, p<.05]$. Separate $t$ tests on the differences between old and new stimuli (see Table 4 for old-new means) revealed that younger 2 ndtimers exceeded younger 1 st-timers $[t(55)=4.44, p<$ $.05]$, but older 2 nd-timers did not differ significantly from older 1st-timers $[t(57)=1.42, p>.05]$.

For erroneous responses, there was no overall difference between younger and older subjects $(6.0 \%$ and $5.9 \%$, respectively; $F<1)$. The interaction between experience and stimulus type did not reach significance $[F(1,112)=$ $1.82, p>.05]$, but there was a significant three-way interaction $[F(1,112)=6.32, p<.05]$. Again, separate $t$ tests were performed on old-new differences to examine this interaction: younger 2 nd-timers did not differ from younger 1st-timers $[t(55)=-0.91, p>.05]$, whereas older 2 nd-timers exceeded older 1 st-timers $[t(57)=2.53$, $p<.02$ ].

For blank responses, there was a significant overall effect of age group $[38.2 \%$ vs. $61.3 \% ; F(1,112)=52.14$, $p<.05]$. The interaction between experience and stimulus type was significant $[F(1,112)=20.72, p<.05]$, but there was no three-way interaction with age group $(F<1)$.

To summarize, it would appear that there is evidence of very long term priming for younger subjects. Thus, it can be seen in Table 4 that younger 2 nd-timers were more likely to correctly name old stimuli (i.e., those they saw 22 months earlier) than to correctly name new stimuli, as compared with 1 st-timers (who were seeing both old and new stimuli for the first time). In contrast, there was no evidence of very long term priming for older subjects in terms of correct responses. However, older 2nd-timers were more likely to erroneously name old stimuli than to erroneously name new stimuli, as compared with older 1 st-timers.

It is interesting to compare this pattern of results with that of Experiment 1. In that case, the increase in correct surname responses $(\mathrm{CC}+\mathrm{EC}+\mathrm{BC})$ from Run 1 to Run 2 was very similar for younger and older subjects $(6.6 \%$ and $6.8 \%$, respectively). However, for erroneous surnames (CE + EE + BE), the increase from Run 1 to Run 2 was significantly smaller for younger subjects than for older subjects $[1.0 \%$ and $3.0 \%$, respectively; $t(82)=-2.10$, $p<.05]$. In other words, there is evidence in both experiments of a greater increase in erroneous responses with repetition for older subjects than for younger subjects. This suggests that at least some of the repetition priming effect in older subjects may be attributable to a difference in response criterion between primed and unprimed stimuli. That is, they may be more willing to offer a naming response to stimuli they had seen minutes or months before, perhaps on the basis of a sense of familiarity (see Bartlett, 1993).

In contrast, the present data from the younger age group provide striking evidence of very long term repetition priming, as defined by a true facilitation of stimulus processing as the result of a previous encounter with the same stimulus. Thus, there was a significant increase in correct responses, without any increase in erroneous responses. There are several points to emphasize about this effect. Note that it cannot be attributed to general skill learning, because the comparison was between old and new items. Nor can it be attributed to an overall difference in difficulty between the old and new sets of stimuli, be-

Table 4

Experiment 2: Means and Standard Deviations of Correct, Erroneous, and Blank Surname Responses to Old and New Stimuli and the Differences Between Them (Old-New)

\begin{tabular}{|c|c|c|c|c|c|}
\hline \multirow[b]{2}{*}{ Subjects } & \multirow[b]{2}{*}{ Stimuli } & \multicolumn{2}{|c|}{ Younger Subjects } & \multicolumn{2}{|c|}{ Older Subjects } \\
\hline & & $M$ & $S D$ & $M$ & $S D$ \\
\hline \multicolumn{6}{|c|}{ Correct surname } \\
\hline 2nd-timers & Old $(\%)$ & 63.1 & 19.4 & 37.4 & 19.2 \\
\hline & New $(\%)$ & 51.5 & 18.2 & 31.3 & 16.6 \\
\hline & Old-New (\%) & 11.7 & 9.8 & 6.1 & 10.4 \\
\hline 1st-timers & Old $(\%)$ & 54.0 & 20.6 & 32.3 & 20.6 \\
\hline & New $(\%)$ & 54.7 & 18.3 & 30.2 & 15.1 \\
\hline & Old-New $(\%)$ & -0.7 & 11.2 & 2.1 & 11.2 \\
\hline \multicolumn{6}{|c|}{ Erroneous surname } \\
\hline 2nd-timers & Old $(\%)$ & 5.8 & 4.8 & 9.0 & 6.1 \\
\hline & New $(\%)$ & 5.0 & 3.5 & 4.3 & 4.0 \\
\hline & Old-New $(\%)$ & 0.8 & 4.7 & 4.7 & 5.7 \\
\hline 1st-timers & Old $(\%)$ & 7.5 & 5.4 & 5.7 & 5.0 \\
\hline & New $(\%)$ & 5.6 & 4.5 & 4.6 & 2.6 \\
\hline & Old-New $(\%)$ & 1.9 & 4.1 & 1.1 & 4.9 \\
\hline \multicolumn{6}{|c|}{ Blank surname } \\
\hline 2nd-timers & Old $(\%)$ & 31.0 & 17.9 & 53.6 & 18.7 \\
\hline & New $(\%)$ & 43.5 & 17.4 & 64.5 & 17.7 \\
\hline & Old-New $(\%)$ & -12.5 & 9.9 & -10.8 & 11.8 \\
\hline \multirow[t]{3}{*}{ lst-timers } & Old $(\%)$ & 38.5 & 20.0 & 62.0 & 19.1 \\
\hline & New $(\%)$ & 39.7 & 17.0 & 65.2 & 15.4 \\
\hline & Old New $(\%)$ & -1.2 & 12.0 & -3.2 & 10.6 \\
\hline
\end{tabular}

Note-Old stimuli, stimuli used in both Experiments 1 and 2; new stimuli, stimuli used in Experiment 2 only. 2 nd-timers, subjects who participated in both Experiments 1 and $2 ; 1$ st-timers, subjects who participated in Experiment 2 only. Totals do not always add up to $100 \%$ because of rounding to one decimal place. Similarly, old-new is not always exactly equal to the difference between old and new as presented here. 
cause 2nd-timers were compared with 1st-timers. Most remarkably, the size of the effect---as measured by comparing 2nd-timers and 1st-timers on the difference between correct surname responses to old and new stimuli of $12.4 \%(11.7+0.7$ from Table 4$)$-is even greater than the increase of $6.6 \%$ in correct surname responses observed in Experiment 1 for younger subjects from Run 1 to Run 2 (see Appendix). However, it should be noted that this comparison is between four exposures 22 months previously (Experiment 2 ) and a single exposure $11 \mathrm{~min}$ previously (Experiment 1). Perhaps a more appropriate comparison is with the increase in correct responses from Run 1 to Run 4 in Experiment 1 of 12.8\% (i.e., the effect of three exposures at $11 \mathrm{~min}, 22 \mathrm{~min}$, and $33 \mathrm{~min}$ previously). Even so, it appears that repetition priming in the younger age group is largely unaffected by an increase in delay from minutes to 22 months. This is particularly surprising in view of the fact that the subjects would have encountered the names and faces of both old and new stimuli many times outside the laboratory during the intervening 22 months.

\section{GENERAL DISCUSSION}

First, to summarize the main findings of this study, in Experiment 1, the subjects were asked to name a set of famous faces four times over the course of a session. As expected from previous studies (see, e.g., Maylor \& Valentine, 1992), younger subjects in their 50s and 60 s were more successful at retrieving the correct name than were older subjects in their $70 \mathrm{~s}$ and $80 \mathrm{~s}$. There was significant improvement in performance with repeated attempts at naming - with blank responses on the first run becoming correct responses by the fourth run. This improvement can be attributed to implicit memory for specific stimuli rather than to general effects of practice. Importantly, in terms of correct responses, younger and older subjects benefited equally from repeated attempts at naming, and this remained the case when age differences in initial levels of performance were statistically taken into account. For the same subjects and over a similar retention interval, there was a highly significant age-related impairment in a picture recognition test. Thus, we have evidence of a marked contrast between preserved implicit memory (as indicated by improvements in naming over repeated attempts) and impaired explicit memory (picture recognition) with aging. In addition, it was shown that aging and repetition had qualitatively similar effects, such that the percentage of naming responses that included both the correct first name and the correct surname was greater for younger subjects than for older subjects and greater with repeated attempts.

In Experiment 2, the subjects who had participated in Experiment 1 returned 22 months later. In comparison with a control group, these subjects were more likely to produce responses (whether correct or erroneous) to famous faces that they had seen before than they were to new faces. For older subjects, this was because of a sig- nificant increase in erroneous responses, suggesting that a less conservative response criterion was applied to familiar stimuli. Note that, although name retrieval in the older age group was not actually improved by prior exposure to the stimuli 22 months earlier, there was nevertheless a significant influence on performance. Thus, for elderly subjects with a mean age of 76 , there is evidence that some effect of processing specific stimuli for only $40 \mathrm{sec}$ per item can be detected even after a delay of 22 months.

For younger subjects who participated in both experiments (mean age of 59), the significant increase in naming responses in Experiment 2 was attributable to correct rather than to erroneous responses, representing a true facilitation of processing because of prior exposure. Remarkably, this repetition priming effect was no smaller after a retention interval of 22 months (Experiment 2) than after retention intervals of up to an hour (Experiment 1 ), whereas explicit memory would surely be expected to decline from minutes to months. In agreement with Mitchell and Brown's (1988) conclusion from their experiment with a 6-week retention interval, "perhaps some residual effect of naming a picture persists indefinitely" (p. 220). To locate the present result more precisely within the Bruce and Young (1986) model would require further experimentation in which, for example, context was manipulated (same vs. different laboratory) or different views of the same people were used (see Bruce, Carson, Burton, \& Kelly, in press; Flude, Ellis, \& Young, 1993). The important point here is that there was a significant age-related deficit in very long term repetition priming in Experiment 2, consistent with explicit memory measures of recall and recognition over long retention intervals in comparable populations of subjects.

The first objective of this study was to look for evidence of a dissociation between preserved implicit memory and impaired explicit memory in old age. As discussed in the introduction, a recent meta-analysis by La Voie and Light (1994) suggested that the dissociation is only partial and that a slight decline in implicit memory with aging emerges when trends are combined across studies. However, their analysis was conducted on tasks that may be particularly prone to contamination from explicit memory. In the present study, the possibility of such contamination was minimal for a number of reasons. First, the task in both experiments was picture-naming under time-limited conditions. As Mitchell (1993) has argued, such performance is unlikely to be influenced by subjects' conscious recollection of earlier encounters with the stimuli (unlike tasks such as homophone spelling, word stem completion, etc.). Moreover, at least two aspects of Experiment 2 in particular would discourage any deliberate use of conscious recollection: (1) explicit memory for stimuli seen for a maximum of only $40 \mathrm{sec}$ would be very weak after 22 months, and (2) the ratio of old to new stimuli was low (1:3). Because of these precautions, the results of the present study therefore provide strong evidence against the preservation of implicit 
memory with aging, at least over a very long retention interval of 22 months (Experiment 2). For much shorter retention intervals of up to an hour (Experiment 1), the conclusion is perhaps less clear. Thus, repeated attempts at naming produced almost identical increases in correct responses for younger and older subjects, but there was also some evidence of the effect observed in Experiment 2 - that is, a greater increase in erroneous responses for older subjects than for younger subjects. It is suggested that further work is required to explore the possibility raised by these results that some demonstrations of preserved implicit memory with aging may represent different response criteria applied to familiar and unfamiliar stimuli by older subjects rather than true repetition priming, as defined by the facilitation of processing of a previously encountered stimulus.

The second main objective of the present study was to examine whether aging and nonrecent use have qualitatively similar effects on word retrieval, as suggested by Burke et al. (1991). This issue was addressed in Experiment 1 by looking at partial versus full name retrieval: Younger subjects were more likely to produce the full name than were older subjects, and subjects were more likely to produce the full name with repeated attempts. This suggests that aging and priming have similar effects on name retrieval (but in opposite directions). Thus, being young rather than old, or being in the primed condition rather than in the unprimed condition, increased the probability that blank responses were resolved to partially correct responses and that partially correct responses were resolved to fully correct responses within the limited time available for proper name retrieval. In other words, the successful retrieval of a person's full name is more likely if connections between nodes in the network are not weakened by either old age or nonrecent use.

Finally, an unexpected finding from Experiment 1 was that subjects were more successful in retrieving surnames than in retrieving first names. This highly robust effect was significant across both subjects and items. Previous research on memory for people's names has not usually considered performance separately in terms of first names and surnames (see G. Cohen \& Burke, 1993, for a review). A recent exception is a study by Jones and Rabbitt (1994) in which subjects were presented with a list of names and were asked later to recall them. There was no overall difference between memory for first names and surnames; however, for pairs of names in which one element was common and the other was rare, there was a local distinctiveness effect, such that the common element was less well recalled than the rare element. It is certainly the case that the first names in the present study were generally more common than the surnames, in terms of the numbers of people that subjects would know who shared the same name. However, it has been argued that the conclusions from a paired associate learning experiment such as Jones and Rabbitt are not necessarily relevant to data from a test of the steady state of a system such as the retrieval of famous people's names (see Bruce,
Burton, \& Walker, 1994). An alternative explanation for the present result was suggested earlier - that is, the names of famous people are often encountered as surnames alone (particularly politicians and sports personalities) but rarely as first names alone. Further research would be required to distinguish between these possibilities and also to explore the consequences of relatively greater sharing of first names than of surnames within interactive activation and competition (IAC) accounts of person identification (see, e.g., Brédart et al., 1995; Burton \& Bruce, 1993), which have not, as yet, fully implemented the separate retrieval of the two elements of people's names.

\section{REFERENCES}

Bartlett, J. C. (1993). Limits on losses in face recognition. In J. Cerella, J. Rybash, W. Hoyer, \& M. L. Commons (Eds.), Adult information processing: Limits on loss (pp. 351-379). San Diego: Academic Press.

Brédart, S., Valentine, T., Calder, A., \& Gassi, L. (1995). An interactive activation model of face naming. Quarterly.Journal of Experimental Psychology, 48A, 466-486.

BRown, A. S., \& Mitchell, D. B. (1994). A reevaluation of semantic versus nonsemantic processing in implicit memory. Memory \& Cognition, 22, 533-541.

Bruce, V., Burton, A. M., \& WALKer, S. (1994). Testing the models? New data and commentary on Stanhope \& Cohen (1993). British Journal of Psychology, 85, 335-369.

Bruce, V., Carson, D., Burton, M., \& Kelly, S. (in press). Primetime advertisements: Repetition priming of faces seen on subject recruitment posters. Memory \& Cognition.

Bruce, V., \& Young, A. W. (1986). Understanding face recognition. British Journal of Psychology, 77, 305-327.

Burke, D. M., MacKay, D. G., WorThley, J. S., \& Wade, E. (1991). On the tip of the tongue: What causes word finding failures in young and older adults? Journal of Memory \& Language, 30, 542-579.

Burton, A. M., \& Bruce, V. (1993). Naming faces and naming names: Exploring an interactive activation model of person recognition. Memory, 1, 457-480.

Burton, A. M., Bruce, V., \& Johnston, R. A. (1990). Understanding face recognition with an interactive activation model. British Journal of Psychology, 81, 361-380.

CAVE, C. B., \& SquiRE, L. R. (1992). Intact and long-lasting repetition priming in amnesia. Journal of Experimental Psychology: Learning, Memory, \& Cognition, 18, 509-520.

Cohen, G., \& Burke, D. M. (1993). Memory for proper names: A review. Memory, 1, 249-263.

Cohen, G., \& Faulkner, D. (1986). Memory for proper names: Age differences in retrieval. British Journal of Developmental Psychology, 4, 187-197.

COHEN, J. (1988). Statistical power analysis for the behavioral sciences (2nd ed.). Hillsdale, NJ: Erlbaum.

Craik, F. I. M., \& Jennings, J. M. (1992). Human memory. In F. I. M. Craik \& T. A. Salthouse (Eds.), The handbook of aging and cognition (pp. 51-110). Hillsdale, NJ: Erlbaum.

DONALDSON, W. (1992). Measuring recognition memory. Journal of Experimental Psychology: General, 121, 275-277.

DuCHEK, J. M., \& BALOTA, D. A. (1993). Sparing activation processes in older adults. In J. Cerella, J. Rybash, W. Hoyer, \& M. L. Commons (Eds.), Adult information processing: Limits on loss (pp. 383-406). San Diego: Academic Press.

Ferris, S. H., Crook, T., Clark, E., McCarthy, M., \& Rae, D. (1980). Facial recognition memory deficits in normal aging and dementia. Journal of Gerontology, 35, 707-714.

Flude, B. M., Ellis, A. W., \& Young, A. W. (1993, September). Longterm repetition priming of familiar faces. Paper presented at International Conference on Face Processing, Cardiff, Wales.

GRAF, P., \& SCHACTER, D. L. (1985). Implicit and explicit memory for 
new associations in normal and amnesic subjects. Journal of Experimental Psychology: Learning, Memory, \& Cognition, 11, 501-518.

GRIER, J. B. (1971). Nonparametric indexes for sensitivity and bias: Computing formulas. Psychological Bulletin, 75, 424-429.

$J_{\mathrm{ACOBY}}$ L. L. (1991). A process dissociation framework: Separating automatic from intentional uses of memory. Journal of Memory \& Language, 30, 513-541.

JENNINGS, J. M., \& JACOBY, L. L. (1993). Automatic versus intentional uses of memory: Aging, attention, and control. Psychology \& Aging, 8, 283-293.

JoNES, S. J., \& RABBITT, P. M. A. (1994). Effects of age on the ability to remember common and rare proper names. Quarterly Journal of Experimental Psychology, 47A, 1001-1014.

KOLERS, P. A. (1976). Reading a year later. Journal of Experimental Psychology: Human Learning \& Memory, 2, 554-565.

LA VoIE, D., \& Light, L. L. (1994). Adult age differences in repetition priming: A meta-analysis. Psychology \& Aging, 9, 539-553.

LIGHT, L. L. (1991). Memory and aging: Four hypotheses in search of data. Annual Review of Psychology, 42, 333-376.

MACKAY, D. G., \& BurKE, D. M. (1990). Cognition and aging: A theory of new learning and the use of old connections. In T. M. Hess (Ed.), Aging and cognition: Knowledge organization and utilization (pp. 213-263). Amsterdam: Elsevier, North-Holland.

MAYLOR, E. A. (1990). Recognizing and naming faces: Aging, memory retrieval, and the tip of the tongue state. Journal of Gerontology: Psychological Sciences, 45, P215-226.

MAYLOR, E. A. (1991). Recognizing and naming tunes: Memory impairment in the elderly. Journal of Gerontology: Psychological Sciences, 46, P207-217.

MAYLOR, E. A. (1993). Aging and forgetting in prospective and retrospective memory tasks. Psychology \& Aging, 8, 420-428.

MAYLOR, E. A. (1995). Effects of aging on the retrieval of common and proper names. Facts \& Research in Gerontology (Suppl.), 55-73

MAYLOR, E. A. (1996). Age-related impairment in an event-based prospective memory task. Psychology \& Aging, 11, 74-78.

MAYLOR, E. A. (1997). Proper name retrieval in old age: Converging evidence against disproportionate impairment. Aging, Neuropsychology, \& Cognition, 4, 211-226.

MAYLOR, E. A., \& VALENTINE, T. (1992). Linear and nonlinear effects of aging on categorizing and naming faces. Psychology \& Aging, 7, 317-323.

MitCheLL, D. B. (1989). How many memory systems? Evidence from aging. Journal of Experimental Psychology: Learning, Memory, \& Cognition, 15, 31-49.

MitCHELl, D. B. (1993). Implicit and explicit memory for pictures: Multiple views across the lifespan. In P. Graf \& M. E. J. Masson (Eds.), Implicit memory: New directions in cognition, development, and neuropsychology (pp. 171-190). Hillsdale, NJ: Erlbaum.

MrTCHELl, D. B., \& Brown, A. S. (1988). Persistent repetition priming in picture naming and its dissociation from recognition memory. Journal of Experimental Psychology: Learning, Memory, \& Cognition, 14, 213-222.

Mitchell, D. B., Brown, A. S., \& Murphy, D. R. (1990). Dissociations between procedural and episodic memory: Effects of time and aging. Psychology \& Aging, 5, 264-276.

NyBERG, L., \& TULVING, E. (1996). Classifying human long-term memory: Evidence from converging dissociations. European Journal of Cognitive Psychology, 8, 163-183.

PARkin, A. J. (1993). Implicit memory across the lifespan. In P. Graf \& M. E. J. Masson (Eds.), Implicit memory: New directions in cognition, development, and neuropsychology (pp. 191-206). Hillsdale, NJ: Erlbaum.

Rabbitt, P., Donlan, C., Bent, N., McInnes, L., \& Abson, V. (1993). The University of Manchester Age and Cognitive Performance Research Centre and North East Age Research longitudinal programmes, 1982-1997. Zeitschrift für Gerontologie, 26, 176-183.

Rabbitt, P., Maylor, E., McInnes, L., Bent, N., \& Moore, B. (1995). What goods can self-assessment questionnaires deliver for cognitive gerontology? Applied Cognitive Psychology, 9, S127-S152.
Rastle, K. G., \& Burke, D. M. (1996). Priming the tip of the tongue: Effects of prior processing on word retrieval in young and old adults. Journal of Memory \& Language, 35, 586-605.

SALTHOUSE, T. A. (1991), Theoretical perspectives on cognitive aging. Hillsdale, NJ: Erlbaum

SCHACTER, D. L. (1987). Implicit memory: History and current status. Journal of Experimental Psychology: Learning, Memory, \& Cognition, $13,501-518$

SCHACTER, D. L. (1995). Implicit memory: A new frontier for cognitive neuroscience. In M. S. Gazzaniga (Ed.), The cognitive neurosciences (pp. 815-824). Cambridge, MA: MIT Press

Schacter, D. L., Kinlstrom, J. F., Kaszniak, A. W., \& ValdiSERRI, M. (1993). Preserved and impaired memory functions in elderly adults. In J. Cerella, J. Rybash, W. Hoyer, \& M. L. Commons (Eds.), Adult information processing: Limits on loss (pp. 383-406). San Diego: Academic Press.

Sloman, S. A., Hayman, C. A. G., Ohta, N., Law, J., \& Tulving, E (1988). Forgetting in primed fragment completion. Journal of Experimental Psychology: Learning, Memory, \& Cognition, 14, 223-239.

Smith, A. D., \& Winograd, E. (1978). Adult age differences in remembering faces. Developmental Psychology, 14, 443-444.

Squire, L. R., \& KNowlton, B. J. (1995). Memory, hippocampus, and brain systems. In M. S. Gazzaniga (Ed.), The cognitive neurosciences (pp. 825-837). Cambridge, MA: MIT Press.

VAlentine, T., Brennen, T., \& Brédart, S. (1996). The cognitive psychology of proper names. London: Routledge.

WECHSLER, D. (1981). Manual for the Wechsler Adult Intelligence Scale-Revised. New York: Psychological Corporation.

\section{NOTES}

1. Undergraduate students $(n=44)$ were asked to name 120 different famous faces in four blocks of 30 trials over the course of an experimental session. For eight of the stimuli, the order of presentation was counterbalanced across sessions, so that it was possible to examine general practice effects unconfounded by item difficulty with this subset of stimuli. Naming performance actually dropped slightly over the four blocks, but the effect was not significant $(p>.05)$. A similar analysis was performed on the data from the present Experiment 2, which also revealed a nonsignificant drop in naming performance over the course of a session. In other words, there is no evidence of a general practice effect in this task.

2. Note that the means in the Appendix are less informative as to the way in which responses changed across runs. In fact, improvement was due, not only to the direct conversion of $\mathrm{BB}$ responses to $\mathrm{CC}$ responses, but also, for example, to the promotion of $\mathrm{BB}$ responses to $\mathrm{BC}$ responses and of $\mathrm{BC}$ responses to $\mathrm{CC}$ responses. In other words, the apparent stability over the four runs for some intermediate responses in the Appendix may be deceptive. Another point to note is that, once subjects had successfully retrieved the correct name for a particular stimulus, they almost never reverted back to a blank response on subsequent runs.

3. The data from Runs 1 and 4 only were entered into the ANOVA based on items.

4. The data from one older subject were not included in the analysis because her scores on this measure of $0 \%, 100 \%, 100 \%$, and $100 \%$ in Runs 1-4 were from the only item she was able to name.

5 . Highly significant differences between the two age groups were also found on several other measures of explicit memory, including immediate and delayed free recall of a list of 10 words, immediate recall of visual shapes and spatial locations, cumulative learning of a list of 15 words, and prospective memory (see Maylor, 1993, for details).

6. It can be noted that the main result of Experiment 1 (i.e., parallel improvements for younger and older subjects with repetition) was the same regardless of whether the data were analyzed in terms of the correct full name or the correct surname.

7. Two of the 90 new stimuli were members of the royal family. The data from these items were discarded because of ambiguity over the correct surname. 
APPENDIX

Experiment 1: Mean Percentages $(M)$ and

Standard Deviations $(S D)$ for the Nine Possible

Responses in Each of the Four Runs for

Younger Subjects and Older Subjects

\begin{tabular}{|c|c|c|c|c|c|c|c|c|}
\hline \multirow[b]{2}{*}{ Responses } & \multicolumn{2}{|c|}{ Run 1} & \multicolumn{2}{|c|}{ Run 2} & \multicolumn{2}{|c|}{ Run 3} & \multicolumn{2}{|c|}{ Run 4} \\
\hline & $M$ & $S D$ & $M$ & $S D$ & $M$ & $S D$ & $M$ & $S D$ \\
\hline \multicolumn{9}{|c|}{ Younger subjects } \\
\hline $\mathrm{CC}$ & 48.8 & 20.9 & 56.9 & 20.8 & 62.4 & 19.9 & 64.3 & 20.2 \\
\hline $\mathrm{EC}$ & 1.7 & 2.5 & 2.3 & 3.0 & 1.9 & 2.8 & 1.8 & 3.0 \\
\hline $\mathrm{BC}$ & 7.2 & 5.5 & 5.1 & 4.9 & 3.9 & 4.1 & 4.4 & 4.9 \\
\hline $\mathrm{CE}$ & 0.4 & 1.1 & 0.6 & 1.5 & 0.9 & 1.8 & 0.8 & 2.1 \\
\hline $\mathrm{EE}$ & 3.6 & 4.0 & 4.5 & 4.5 & 5.5 & 5.0 & 5.6 & 5.2 \\
\hline $\mathrm{BE}$ & 1.3 & 2.2 & 1. & 2 & 1.0 & 1.8 & 1.3 & 2.3 \\
\hline $\mathrm{CB}$ & 2.1 & 3.1 & 1.6 & 2. & 1.0 & 2.1 & 0.8 & 1.8 \\
\hline EB & 0.9 & 2.1 & 0.4 & 1.1 & 0.4 & 1.1 & 0.6 & 1.3 \\
\hline DD & 34.0 & 19.0 & 27.4 & 17.4 & 23.0 & 15.7 & 20.5 & 14.8 \\
\hline \multicolumn{9}{|c|}{ Older subjects } \\
\hline $\mathrm{CC}$ & 24.4 & 20.1 & 33.1 & 20.7 & 37.6 & 21.5 & 40.1 & 22.3 \\
\hline $\mathrm{EC}$ & 1.2 & 2.1 & 1.3 & 2.4 & 1.2 & 2.4 & 1.2 & 2.4 \\
\hline $\mathrm{BC}$ & 12.0 & 8.6 & 10.0 & 9.0 & 10.2 & 8.8 & 10.1 & 9.5 \\
\hline $\mathrm{CE}$ & 0.3 & 1.2 & 0.4 & 1.1 & 0.5 & 1.2 & 0.7 & 1.7 \\
\hline $\mathrm{EE}$ & 2.1 & 3.0 & 4.4 & 4.3 & 5.1 & 5.2 & 5.4 & 5.3 \\
\hline $\mathrm{BE}$ & 2.8 & 3.4 & 3.4 & 3.3 & 3.8 & 4.8 & 3.9 & 5.4 \\
\hline $\mathrm{CB}$ & 2.9 & 3.4 & 2.7 & 3.8 & 1.7 & 2.7 & 1.7 & 2.9 \\
\hline EB & 1.5 & 2.7 & 1.1 & 1.9 & 1.0 & 2.3 & 1.5 & 2.5 \\
\hline $\mathrm{BB}$ & 52.9 & 18.6 & 43.6 & 19.1 & 38.8 & 19.1 & 35.5 & 19.2 \\
\hline
\end{tabular}

Note-The first letter in each pair refers to the first name; the second letter refers to the surname. $\mathrm{C}$, correct; $\mathrm{E}$, error; B, blank. Totals do not always add up to $100 \%$, because of rounding to one decimal place.

(Manuscript received February 23, 1996;

revision accepted for publication January $25,1997$. 